\title{
Study of the Quality Reputation of Military Automobile Polit Training
}

\author{
Muqi Xiao \\ Logistics University of People's military Force, Tianjin, P.R. China \\ 1107481784@qq.com
}

Keywords: Military; Automobile pilot; Training quality; Reputation system

\begin{abstract}
Automobile driver training is an important part of the military force training, quality driver training, directly affect the army security force generation and enhance combat capability. In the evaluation of driver training quality, is to strengthen the team construction, an important measure to improve the transportation of materials support ability and the rapid mobility. To research and Analysis on the current car driver training in the assessment of quality evaluation system problems, find a better car driver training quality, the automobile driver training will play a great role in promoting. This article conducts the analysis research from home and abroad and the military force vehicle driver training quality assessment model, research on comprehensive domestic training quality evaluation system, through the use of the analytic hierarchy process, combined with the assessment of the actual problem of military driver training status and driver training quality, through research and analysis of sufficient, established a set of scientific, reasonable and accurate driver training quality evaluation system, the evaluation system is verified by practical application. Through the research on the evaluation of driver training quality, ensure that the driver's training quality, ensure that the armed forces transportation guarantee capability and fast transport capacity.
\end{abstract}

\section{Research on Training Quality Evaluation System Based on Analytic Hierarchy Process}

Using the Analytic Hierarchy Process (AHP) to Determine the Weight. Structure Hierarchy Model. The factors which affect the quality of driver training are organized and hierarchical, and a hierarchical structure model is constructed. In this model, the hierarchy can be divided into three categories: top (the target layer) has only one element, is the quality of driver training is analysis of predetermined goals or desired results; intermediate layer (criteria) including the for the realization of the goal involved the middle part, a total of 3 first level indicators; the bottom (scheme) layer includes the specific evaluation index, 11 second grade indexes. The hierarchical model constructed is shown in Table 1.

Table 1 Driver training quality evaluation system mode1

\begin{tabular}{|c|c|c|}
\hline \multicolumn{3}{|c|}{ Driver quality assessment } \\
\hline Personal quality index x1 & Learning ability & $\begin{array}{l}\text { Ability to accomplish tasks } \\
\text { index x } 3\end{array}$ \\
\hline $\begin{array}{l}\text { Ideological and moral } \\
\text { quality y1 }\end{array}$ & Driving knowledge y5 & Satisfaction degree y9 \\
\hline Basic physical fitness y2 & $\begin{array}{l}\text { Action and professional skills } \\
\text { y6 }\end{array}$ & $\begin{array}{l}\text { Action and professional skills } \\
\text { y10 }\end{array}$ \\
\hline Special physical quality y3 & safety consciousness y7 & $\begin{array}{l}\text { Performance improvement } \\
\text { y11 }\end{array}$ \\
\hline Psychological quality y4 & Strain capacity y8 & \\
\hline
\end{tabular}

Construct Two Two Comparison Judgment Matrix. Introductting a number of experts using the Delphy method (Delphi), through the questionnaire survey method, and based on driving training experts, the valuable advice of front-line workers were corrected. In accordance with the 1-9 scale of the index system of the importance of each index assignment (see Table 2), the results of a comprehensive expert scoring after the two two comparison judgment matrix. 
A reasonable two two comparison judgment matrix is constructed as $A, A=\{$ aij $\}$, and the judgment matrix satisfies the "aij $>0$, aij=1/bij, aij=1, called the positive and negative judgment matrix.

First level index comparison matrix design: Personal quality indicators, learning indicators, comprehensive indicators. Personal quality index, after extensive solicitation of opinions, to collect opinions of integrate personal quality is to assess the quality of driver training for the hard conditions; learning ability index is basic index of the pilot evaluation, is also hard conditions, but after personal index; complete mission capability is a means of objective evaluation of driver, so set personal quality index is the most important, learning ability and quality index of times, and finally the ability to complete the task index and level is an important indicator of the degree of order for:

Index of individual quality $>$ learning index $>$ to finish the task ability index

In this paper, a key indicator of the degree is determined according to the military force driving training development situation, the relevant administrative departments to improve the guiding the direction of driving training quality and not according to the index of importance to the evaluation of the object were paid points.

After the comparison of 3 indicators two two, the most important indicators and relatively unimportant indicators were set to 4 points and 1 points, the more important indicators for 3 points, so that the first level indicators of the two two comparison matrix $\mathrm{Al}$ as follows:

$$
\mathrm{A} 1=\begin{array}{ccc}
1 & 4 / 3 & 4 \\
3 / 4 & 1 & 3 \\
1 / 4 & 1 / 3 & 1
\end{array}
$$

Table 2 1-9 Scale meaning

\begin{tabular}{cc}
\hline Relative importance (aij) & meaning \\
\hline 1 & Equally important \\
3 & Slightly important \\
5 & Very important \\
7 & Obviously important \\
9 & Absolutely important \\
$2,4,6,8$ & Between two adjacent importance \\
\hline
\end{tabular}

The design of the two level index comparison matrix. Taking the two level indicators of personal quality indicators as an example, including the ideological and moral quality, basic physical quality, psychological quality indicators. Due to the soldiers must have the quality of Ideological and moral quality; basic physical quality is basic quality, no good physical quality cannot be effectively driving action, and special physical quality is required for the special task, complete the psychological quality as a very important factor, also cannot be ignored. So the importance of each index is sorted as:

Basic physical qualities = ideological and moral qualities $>$ psychological quality $>$ special physical qualities

Four indicators of pairwise comparison, very important indicators and relatively important indexes were set to 5 and 1, very important index for 4 points, the index set of equally important for 1 minute "so that the second level indicators, pairwise comparison matrix BL are as follows:

$$
\text { B1 }=\begin{array}{cccc}
1 & 1 & 5 & 5 / 4 \\
1 & 1 & 5 & 5 / 4 \\
1 / 5 & 1 / 5 & 1 & 1 / 4 \\
4 / 5 & 4 / 5 & 4 & 1
\end{array}
$$

Similarly, according to the above method, we can get the matrix B2 and B3 by comparing the learning index and the comprehensive index two two: 


$$
\mathrm{B} 2=\begin{array}{cccc}
1 & 1 & 5 / 4 & 5 \\
1 & 1 & 5 / 4 & 5 \\
4 / 5 & 4 / 5 & 1 & 4 \\
1 / 5 & 1 / 5 & 1 / 4 & 1
\end{array} \quad \text { B3 } \quad \begin{array}{rrr}
1 & 4 / 3 & 1 \\
3 / 4 & 1 & 3 \\
1 / 4 & 1 / 3 & 1
\end{array}
$$

Calculation Weights. calculate the sum of each column of the matrix A Mij, Mij= $\sum$ aij, $\mathrm{i}=1,2,,, \mathrm{n} ; \mathrm{j}=1,2, \ldots ., \mathrm{n}$;

Calculate the matrix $\mathrm{A}$ in each of the AIJ divided by the sum of its column derived Wij, Wij= aij/Mij , i=1, 2, , , n ;j=1,2,,n;

Calculate the average value of each line $\mathrm{Q}, \mathrm{Q}$ that is the weight of the various indicators, $\mathrm{i}=1$, $2,,, n$ to determine the matrix order;

After the above all, after the steps of the calculation can be an index weight vector phi (see Table 3)

Table 3 The level of index weight vector for $\Phi$

\begin{tabular}{ccccc}
\hline & $\begin{array}{c}\text { Personal } \\
\text { quality index } \\
\text { x1 }\end{array}$ & $\begin{array}{c}\text { Learning } \\
\text { ability index } \\
\text { x2 }\end{array}$ & $\begin{array}{c}\text { Ability to } \\
\text { accomplish tasks } \\
\text { index x3 }\end{array}$ & $\Phi$ \\
\hline $\begin{array}{c}\text { Personal quality index x1 } \\
\text { Learning ability index x2 }\end{array}$ & 1 & $4 / 3$ & 4 & 0.500 \\
$\begin{array}{c}\text { Ability to accomplish tasks } \\
\text { index x3 }\end{array}$ & $1 / 4$ & 1 & 3 & 0.375 \\
\hline
\end{tabular}

Similarly, after the two step level index weight of $\sigma 1 、 \sigma 2 、 \sigma 3$ Vector Table 4 to Table 6 :

Table 4 Level two indexes weight vector for $\sigma 1$

\begin{tabular}{cccccc}
\hline & $\begin{array}{c}\text { Ideological and } \\
\text { moral quality } \\
\text { y1 }\end{array}$ & $\begin{array}{c}\text { Basic physical } \\
\text { fitness y2 }\end{array}$ & $\begin{array}{c}\text { Special physical } \\
\text { quality y3 }\end{array}$ & $\begin{array}{c}\text { Psychological } \\
\text { quality y4 }\end{array}$ & $\sigma 1$ \\
\hline $\begin{array}{c}\text { Ideological and } \\
\text { moral quality y1 }\end{array}$ & 1 & 1 & 5 & $5 / 4$ & 0.333 \\
$\begin{array}{c}\text { Basic physical } \\
\text { fitness y2 }\end{array}$ & 1 & 1 & 5 & $5 / 4$ & 0.333 \\
$\begin{array}{c}\text { Special physical } \\
\text { quality y3 }\end{array}$ & $1 / 5$ & $1 / 5$ & 1 & $1 / 4$ & 0.067 \\
$\begin{array}{c}\text { Psychological } \\
\text { quality y4 }\end{array}$ & $4 / 5$ & $4 / 5$ & 4 & 1 & 0.267 \\
\hline
\end{tabular}

Table 5 Level two indexes weight vector for $\sigma 2$

\begin{tabular}{cccccc}
\hline & $\begin{array}{c}\text { Driving } \\
\text { knowledge y5 }\end{array}$ & $\begin{array}{c}\text { Action and } \\
\text { professional } \\
\text { skills y6 }\end{array}$ & $\begin{array}{c}\text { safety } \\
\text { consciousness } \\
\text { y7 }\end{array}$ & $\begin{array}{c}\text { Strain capacity } \\
\text { y8 }\end{array}$ & $\sigma 2$ \\
\hline $\begin{array}{c}\text { Driving } \\
\text { knowledge y5 } \\
\text { Action and } \\
\text { professional } \\
\text { skills y6 }\end{array}$ & 1 & 1 & $5 / 4$ & 5 & 0.333 \\
& 1 & 1 & $5 / 4$ & 5 & 0.333
\end{tabular}




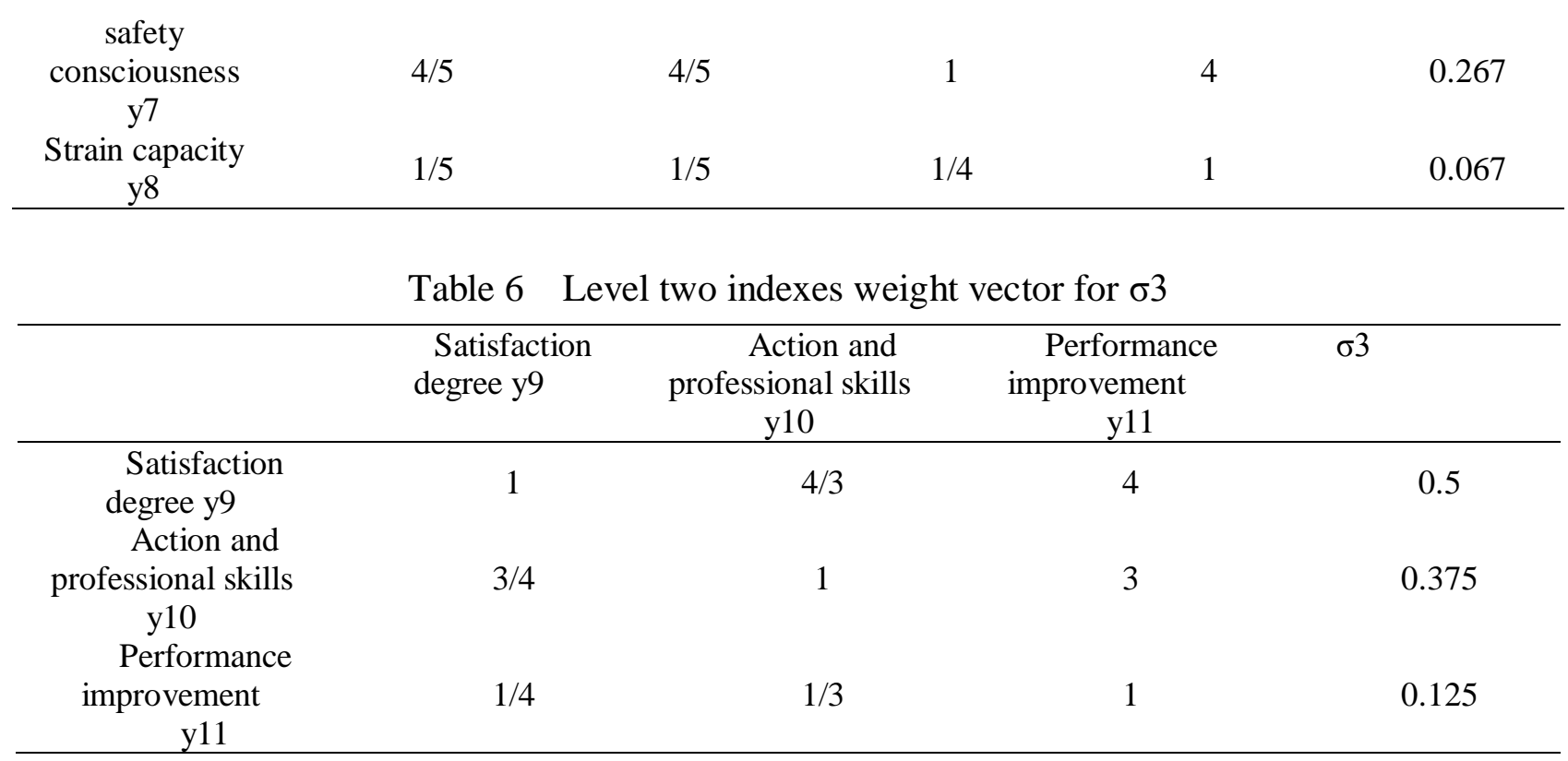

Consistency Test. Check the consistency of pairwise comparison judgment matrix, due to the number of pairwise comparisons, it is impossible to accomplish the same, in the AHP, with the following four steps to complete the test of the two two judgment matrix.

the maximum eigenvalue of the matrix is $\lambda \max , \lambda \max =\sum$ aij $/ \mathrm{n}$;

Consistency index is $\mathrm{CI}, \mathrm{CI}=(\lambda \max -\mathrm{n}) /(\mathrm{n}-1)$ :

By using the average random consistency index table, the average consistency index RI of the same order matrix was found (see table 7).

Table 7 The average random consistency index

\begin{tabular}{ccccccccccc}
\hline $\begin{array}{c}\text { Order } \\
\text { number } \\
\mathrm{n}\end{array}$ & 1 & 2 & 3 & 4 & 5 & 6 & 7 & 8 & 9 & 10 \\
\hline $\mathrm{RI}$ & 0 & 0 & 0.58 & 0.9 & 1.12 & 1.26 & 1.36 & 1.41 & 1.46 & 1.49
\end{tabular}

Calculate the consistency ratio $\mathrm{CR}, \mathrm{CR}=\mathrm{CI} / \mathrm{RI}$

When $\mathrm{RI}=0$ judge matrix is complete consistency; when $\mathrm{Cr}$ is less than or equal to 0.1 , judgment matrix with satisfactory consistency; when $C R>0.1$ judge matrix with satisfactory consistency, with pairwise comparison matrices of the data to be adjusted or abandon.

According to the above calculation principle, the consistency check of the judgment matrix of the first order index is carried out. Through calculation and judgment matrix corresponding small brother lambda $\max =4.175, \mathrm{CI}=0.058, \mathrm{RI}=0.9, \mathrm{CR}=0.065<0.1$, show that $\Phi$ vector corresponding to the judgment matrix is completely consistent.

The consistency check of the two level index decision matrix. Through calculation and judgment matrix of $\sigma 1$ corresponds to the lambda $\max =5.03, \mathrm{CI}=0.008, \mathrm{RI}=1.12, \mathrm{CR}=0.007<0.1$, show that $\sigma 1$ Wei corresponds to the index of the secondary judgment matrix with satisfactory consistency. By calculating $\sigma 2$ corresponds to the judgment matrix of lambda $\max =6.200, \mathrm{CI}=0.040, \mathrm{RI}=1.26$, $\mathrm{CR}=0.032<0.1$, show that 2 corresponds to the index of the secondary judgment matrix with satisfactory consistency. The calculated $\sigma 3$ corresponding.

$\Lambda \max =5.105, \mathrm{CI}=0.026, \mathrm{RI}=1.12, \mathrm{CR}=0.023<0.1$. That $\sigma 3$ judgment matrix with satisfactory consistency of the corresponding vector.

Through the consistency of the first level indicators, two indicators of the test, all of the two judgment matrix has consistency, which shows that the weight of the evaluation index system of the 
pilot training quality evaluation system is reasonable through Delphy Fa estimation.

Calculate the total weight. The target layer in the driver training quality evaluation system is influenced by the first level index and the two level index weight, The weight of each index and the two level indicators can be calculated by calculating the weight vector of each index for the target layer, so as to obtain the total weight $\omega$ of the driver training quality evaluation system (see table 8).

$\omega$ is equal to the product of the first class index and the two level index weight vector.

Table 8 Driver training institution straining quality evaluation system index total weight

\begin{tabular}{ccccc}
\hline Driver quality & \multicolumn{2}{c}{$\Phi(0.5,0.375,0.125)$} & Weight \\
\cline { 2 - 4 } assessment & $\sigma 1$ & $\sigma 2$ & $\sigma 3$ & 0.167 \\
\hline y1 & 0.333 & & & 0.167 \\
y2 & 0.333 & & & 0.034 \\
y3 & 0.067 & & & 0.134 \\
y4 & 0.267 & 0.333 & & 0.125 \\
y5 & & 0.333 & & 0.125 \\
y6 & 0.267 & 0.5 & 0.095 \\
y7 & 0.067 & 0.375 & 0.024 \\
y8 & & 0.125 & 0.063 \\
y9 & & & 0.047 \\
y10 & & & 0.015 \\
y11 & & & \\
\hline
\end{tabular}

\section{Conclusion}

The diagnostic features of driving training quality evaluation system realization is through the use of the training quality evaluation system of driving training quality index score and the expectation scores were compared to find the gap existing, and ultimately to determine the crux affecting the quality of training.

Specific diagnostic steps are as follows:

To determine the evaluation of personnel;

To choose the training of the driver and the expected target of the training of the driver;

Using the driver training quality evaluation system to evaluate the selected target;

Using the index evaluation standard to analyze the index of the gap, and the reason of the existence of the gap. Clear the crux affecting the quality of training, in view of the existing problems of the link, combined with the actual situation, comprehensive analysis to achieve the transformation of the degree of difficulty, the degree of importance to determine the transformation sequence and re-election. To realize the purpose of scientific investment and reasonable transformation.

\section{References}

[1] D.Z. Cai: Evaluation Based on AHP motor vehicle driving training quality (MS., Dalian Maritime University, China 2011), p.26.

[2] L.F. Chen: Guangdong Province motor vehicle driving training quality credit evaluation index system (MS., Guangdong Technology University, China 2011), p.18.

[3] Z.Q. Chen, C.C. Hu, Z.T. Sun: Chinese Academic Research, (2011) No.4 p.80.

[4] R.H. Chen: Generation Enterprise Education, (2008) No.12 p.13.

[5] Y.K. Wang, D. Xia: Communications Science and Technology, (2009) No.2 p.124.

[6] Z.Q. Chen, C.C. Hu, Z.T. Sun: Chinese Academic Research, (2011) No.4 p.80.

[7] R. Wang: Management observation, (2009) No.13 p.186.

[8] R.H. Chen: Modern enterprise education, (2008) No.2 p.13. 
[9] Y. Li, L. Hua, Y. Ma: The Science Education Article Collects, (2009) No.36 p.126.

[10] J.B. Jia, Z.G. Han, J.P. Du, Z.F Zou: Journal of information engineering university, (2010) No.11 p.483. 